he possibly be a proof that Leicester was becoming a nuisance to other towns.

To return to your figure of speech. If a town were built of wood, an efficient brigade would be able to cope with a fire, if it reached the spot on the instant of its outbreak; and this has been our experience for some years in dealing with small-pox. Would it not be well if other towns were to adopt our plan, instead of wringing their hands over the failure of vaccination; and might not the medical journals render good service by recommending strict isolation, as practised in Leicester, in addition, if you will, to vaccination? I hope they will lose no time in doing this.

$$
\text { I am, Sir, your obedient servant, }
$$

Thomas WINDLEx,

Leicester, October 5th. Chairman of the Sanitary Committee.

$*_{*}^{*}$ We accept Mr. Windley's correction that the system of isolation of the healthy who have been exposed to infection as well as those who are suffering from small-pox has not altogether prevented deaths from this disease in Leicester; and we share with him the conviction that this system has been instrumental in preventing until now the epidemic prevalence of the disease. But we are none the less convinced that the system cannot be trusted to replace vaccination, and that Leicester will eventually be brought to hold the same opinion after a lamentable sacrifice of human life.-ED. L.

\section{ON CIRCULAR HOSPITAL WARDS.}

\section{To the Editor of THE LANCET.}

SIR,-In reply to Mr. Snell's letter, published in THE LANCET of the 10th inst., I can only regret that any feeling should be aroused, as I wish, above all things, to be kindly and courteous, and to state only the precise facts. Mr. Snell's anger grieves and surprises me, for, at the worst, we may discuss so dry a subject as the shape of a ward, and entirely differ in our views, without offence, and with the kindliest feelings towards each other. The facts of the case are, so far as I know them, as follows:--

1. The only six hospitals in the United Kingdom which have 500 beds and upwards, are-Edinburgh, Royal, 517; Glasgow, Royal, 584; St. Thomas's, 590; St. Bartholomew's, 676 ; Guy's, 700; and the London-the largest hospital in Great Britain-780.

2. I do not know of any large British hospital that has been built from Mr. Snell's plans; though, of course, 1 know of the enlargement of the Hull Infirmary. The plans designed by Mr. Snell, within my knowledge, are chiefly of Poor-law buildings.

I have received much courtesy from $\mathrm{Mr}$. Snell; I recognise much useful work he has done, and I would not knowingly annoy him or hurt his feelings.

\section{I am, Sir, yours, \&c.}

HENRY C. BURdetT.

The Lodge, Porehester-sqnare, W., Oct. 10th, 1885.

\section{To the Eaitor of THA LANCET.}

SIR,-In the paper read by me upon the above subject at the Leicester Congress, I showed that if the system of constructing circular wards were continued, the benevolent public must be prepared to pay very heavily for the luxury (if it were one), and I estimated the increased cost at about $£ 105,000$ for every 1000 patients. I also showed very plainly that no advantage would accrue from such an increased outlay, but that, on the contrary, the inmates of these circular wards would not be housed under such favourable hygienic conditions as they would be if they continued to occupy the parallelooram-shaped wards. Captain Galton and Professor De Chaumont, two of the most eminent authorities upon the subject of hospital construction, supported my views, and so also did two architects of large practice and experience in these matters; and it will be remembered that $I$ based my assertions upon the writings of some of the most eminent experts in this country

Mr. Burdett, in the communication published in your issue last week, gives a complete denial to all my statements, and occupies more than two pages of your valuable space with the expression of his own opinions upon this important subject, unaided by a single reference to any authority who would support his statements. For this, and for trying to carry his point by contorting facts, he might be excused, but not so where he founds his argument upon misquotations from the work published by Dr. Mouat and myself upon hospital construction. Many of the figures contained in the "table" he says he has compiled from this work are not mine at all, and it will be well, therefore, to bear this in mind when the arguments are read upon which he founds his contentions.

I propose, with your permission, to answer Mr. Burdett's letter fully if you will give me space, but my time is too much occupied this week to do so.

Let me, however, point out how great a responsibility will devolve upon the managers of any institution who would contemplate the further erection of circular wards until my assertions as to its extravagance, and those of the eminent experts mentioned by me, have been answered by some higher and more reliable authority than Mr. H. C. Burdett. II am, Sir, yours obediently,

H. SaxoN SNeII.

* * We regret that our space at the present time will not allow of further lengthened discussion of this subject.ED. L.

\section{REMUNERATION FOR EXTRA MEDICAL SERVICES.}

\section{To the Editor of THE LANCET.}

SrR,-Will you kindly insert the enclosed communication in your issue of this week, and oblige, yours truly, J. WICKHAM BARNES.

Poor-law Medical Officers' Association, Bolt-court, Fleet-street, E.C., Oct. 13th, 1885.

At a meeting of the Council of the Poor-law Medical Officers' Association, held at their rooms, 3, Bolt-court, the subjoined resolution was unanimously adopted:- "That this Council, having perused the correspondence relating to the epidemic of small-pox in Camberwell, regrets to find that two medical members of the Board have unjustifiably, on apparently insufficient grounds, opposed the grant which was proposed to be given to the district medical officer for extra services in visiting and attending a great number of non-pauper cases of small-pox, more especially as at the same meeting a gratuity was granted to the relieving officers for the extra work they had performed in connexion with such cases. And this Council further desires to express its recognition of the courteous and kind consideration exhibited by Dr. Massey in his advocacy of the just claims of such officers."

\section{MANCHESTER.}

\section{(From our own Correspondent.)}

\section{THF MEDICAL SOCIETIES,}

THE Medical Societies have commenced work for the coming session, the first meeting of the Medico-Ethical having been held on the 25th ult. A paper, which led to some discussion, was given by Dr. Tatham, the medica: officer of health for Salford, on the Relation of Health Officers to Local Authorities, in which he took a rather gloomy view of affairs, and pointed out the very msatisfactory position of those officials under the present law, showing that they held office entirely subject to the local authority under which they acted; and that if they in the fulfilment of their duties offended members of their committees, as not unfrequently happened, their lives were made almost unbearable by the treatment they receired. $\mathrm{He}$ was in favour of giving a power of veto to the Locxl Government Board in the case of appointments and dismissal of all medical officers of health. We have now no less than half a dozen societies more or less flourishin: here-viz., the Medical Society; the Pathological Society, in offshoot of the former, which has now entered on a separate existence, and bids fair to become possessed of considerable vitality; the Medico-Ethical; the New Central Medic: Society, which appears likely to be a success judging from the number of its members, which already reaches nearly one hundred; the Medical Students' Debating Society; and. lastly, an Odontological Society, recently formed, under tl. presidency of E. W. Smith, M.R.C.S., and to which most $a_{t}^{2}$ 